\title{
Aspectos da precipitação pluviométrica em um povoamento jovem de Eucalyptus dunnii no Bioma Pampa
}

\author{
Robson Schaff Corrêa ${ }^{1}$ Mauro Valdir Schumacher ${ }^{2}$ Dione Richer Momolli² Camila Berger ${ }^{2}$ \\ ${ }^{1}$ Universidade Federal de Goiás, Câmpus Jatobá - BR 364, km 195, n 3800, Jataí - GO, 75801-615 \\ ${ }^{2}$ Universidade Federal de Santa Maria, Centro de Ciências Rurais, Departamento de Ciências Florestais, Santa Maria - RS, $97105-900$.
}

*Author for correspondence: rs.correa@yahoo.com.br

Received: November 2018 / Accepted: August 2019 /Published: September 2019

\section{Resumo}

A interação de plantios florestais com a precipitação influi tanto no crescimento e desenvolvimento da floresta quanto na disponibilidade de água para percolação e abastecimento do lençol freático, e assim, a fase de desenvolvimento do povoamento é um aspecto relevante a ser observado. Objetivou-se avaliar a precipitação pluviométrica em Eucalyptus dunnii através do monitoramento de um povoamento durante o período de um ano, com início aos 16 meses de idade, no município de Alegrete-RS. A precipitação dentro do povoamento foi mensurada por meio de coletores de precipitação interna e coletores de solução decorrente do escorrimento pelo tronco. Já a precipitação total foi avaliada por coletores de precipitação instalados fora do povoamento e sem interferência do dossel florestal. A interceptação da precipitação pelo povoamento foi de $7 \%$ da precipitação total e a precipitação interna correspondeu a $98 \%$ da precipitação efetiva, sendo os $2 \%$ restantes relativos ao escorrimento pelo tronco. Os valores das formas de interação da precipitação com o povoamento variaram ao longo dos meses de avaliação.

Palavras-chave: Hidrologia florestal; Pluviosidade; Precipitação interna; Interceptação; Escorrimento pelo tronco.

\begin{abstract}
The interaction of forest plantations with precipitation influences both the growth and development of the forest and the availability of water for percolation and water supply, and the development stage of the stands is an important aspect to be observed. Thus, the aim of this work was to evaluate the rain fall in Eucalyptus dunnii through the monitoring of a stand through the period of one year, beginning at 16 months old stand, in the city of Alegrete-RS. The precipitation inside the stand was collected through internal precipitation gauges and the stemflow was collected using stemflow solution gauges. On the other hand, global precipitation was evaluated by precipitation gauges installed outside the stand and without forest canopy interference. The interception of precipitation by stand was $7 \%$ of the total precipitation and the internal precipitation corresponded to $98 \%$ of the effective precipitation, with the remaining $2 \%$ relative to the stemflow. The values of the forms of precipitation with the stand varied throughout the evaluation months.
\end{abstract}

Keywords: Forest Hydrology; Rain; Throughfall; Interception; Stemflow.

\section{Introdução}

O Brasil possui grande potencial florestal para se enquadrar de forma mais abrangente na economia verde e circular, alinhando-se cada vez mais na demanda mundial por produtos ecologicamente corretos e advindos de fontes sustetáveis, como no caso das florestas plantadas e certificadas. Para a máxima produtividade das florestas, de acordo com o Bioma em que está inserida, é fundamental o estudo e entendimento do ciclo hidrológico e sua interação com as mesmas. Uma vez que esse, é determinante para manejar a floresta de forma eficiente e segura antes de sua implementação e durante o desenvolvimento das mesmas, o que permite promover a manutenção e conservação dos recursos naturais a curto e longo prazo.

Com produção de 85 milhões de $\mathrm{m} 3$ de toras destinadas a produção de papele celulose, com valor de $\mathrm{R} \$ 5,2$ bilhões, o Brasil destaca-se como grande produtor florestal no mercado mundial (IBGE 2016). Apresenta-se como o segundo maior produtor de celulose do mundo e oitavo na produção de papel. Com destaque para os plantios de eucalipto, que ocupam 72 $\%$ do total dos 7,84 milhões de hectares de árvores plantadas. Em que também são destinadas com destaque a produção de lenha industrial, carvão vegetal, painéis de madeira e madeira serrada (IBÁ 2017).

Os plantios de eucalipto apresentam muitas vantagens, destacando-se o rápido crescimento em ciclo de curta rotação, a alta produtividade alcançada, bem como, contínua expansão e direcionamento de novos investimentos por parte de empresas de segmentos que utilizam a madeira como matéria prima em seus processos industriais (ABRAF 2010). De modo que, no Estado do Rio Grande do Sul a expansão da silvicultura passou a ocorrer em locais onde não havia expressiva área de florestas plantadas, como as regiões do Bioma Pampa, assim, a área de plantações florestais foi de de 153 mil ha em 2004 para 280 mil ha em 2011, atingindo cerca de 308 mil ha em 2016 (ABRAF 2009 e 2012; IBÁ 2017).

Com isso, houve motivação para a criação do Zoneamento Ambiental para a Atividade de Silvicultura no Rio Grande do Sul, que trata, entre outros pontos, de orientar a atividade de silvicultura visando à conservação ambiental (CONSEMA 2009). Uma das questões ambientais se refere ao ciclo hidrológico, um fenômeno global de circulação fechada de água entre a superfície terrestre, representada por oceanos e continentes, e a atmosfera. Toda a água contida na atmosfera constitui uma fase do ciclo hidrológico, que ocorre no sentido superfície-atmosfera pelo fluxo devido à evapotranspiração e no sentido atmosfera-superfície em face das precipitações, principalmente na forma de chuva (Silveira 1993).

A precipitação de água que atinge o dossel florestal não chega uniformemente à superfície do solo, é interceptada pelas copas das árvores e redistribuída como precipitação interna. Em que é caracterizada pela forma onde a água atinge ou não a copa da árvore e precipita como gota ou como escorrimento pelo tronco, forma onde a água que atinge o solo é proveniente do fluxo através da passagem pelos troncos do dossel (Kimmins 1987). Já o processo de interceptação depende de vários fatores como a característica da precipitação e as condições climáticas, o tipo e a densidade da vegetação, além do período do ano (Tucci 1993).

Somado a isso, conforme as estações do ano a interação da 
água da chuva pelas copas das árvores e pelo escorrimento da mesma pelo tronco transporta nutrientes minerais alterando também o pH da mesma e, assim, contribuindo para o enrequecimento de nutrientes do solo. $\mathrm{O}$ entendimento da dinâmica da floresta possibilita desenvolver um manejo adequado da mesma, permitindo inferir por exemplo, nas taxas de fertilizantes a serem utilizadas (Gonçalves et al. 2004; M arques et al. 2015).

Neste sentido, o presente estudo objetivou avaliar os diferentes aspectos da interação da precipitação pluviométrica com um plantio jovem de Eucalyptus dunnii Maiden.

\section{Material e métodos}

O clima da região de estudo é subtemperado úmido, em que os verões podem apresentar período de seca, com temperatura média anual de $18,6{ }^{\circ} \mathrm{C}$ e precipitação média anual de $1.574 \mathrm{~mm}$ (Maluf 2000).

A região apresenta relevo plano a ondulado, com formação de coxilhas, próximo ao local de estudo havia áreas de campo alterado/degradado em regeneração, afloramentos rochosos, floresta de encosta e banhado e no talhão onde o plantio foi feito havia campo alterado/degradado pela agricultura e pelo pastoreio, com raros focos de arenização (Silviconsult Engenharia 2007a).

No que concerne ao povoamento de Eucalyptus dunnii objeto deste estudo, o plantio foi feito próximo às coordenadas geográficas $29^{\circ} 47^{\prime}, \mathrm{S}$ e $55^{\circ} 17^{\prime} \mathrm{O}$, com espaçamento entre plantas de $2,0 \mathrm{~m}$ entre plantas $\times 3,5 \mathrm{~m}$ entrelinhas.

Em relação ao solo, o povoamento foi implantado em um Latossolo Vermelho Distrófico típico (Silviconsult Engenharia 2007b; Santos et al. 2018), com atributos químicos e físicos, ao início do monitoramento, conforme a Tabela 1.

As operações de implantação seguiram tratamentos silviculturais como controle de formigas, aplicação de herbicida em área total, subsolagem $(50 \mathrm{~cm}$ de profundidade) e fosfatagem em linha, irrigação, adubação de plantio, adubação de cobertura e capinas na linha e na entrelinha. Foram aplicados $300 \mathrm{~kg} \mathrm{ha}^{-1}$ de Fosfato Natural Gafsa em linha no preparo do solo, aos 15 dias foram aplicados $140 \mathrm{~kg}$ $\mathrm{ha}^{-1}$ de NPK 06-30-06 + 0,3\% B e aos 40 e 90 dias foram aplicados $120 \mathrm{~kg} \mathrm{ha}^{-1}$ de NPK 22-01-18 + 0,3\% B + 0,2\% $\mathrm{Cu}$.

Aos 15 e aos 27 meses de idade, respectivamente um mês e meio antes do início e um mês e meio antes do término do monitoramento, foram realizados inventários florestais (Tabela 2).

Tabela 1 - Atributos físicos e químicos da camada de $0-20 \mathrm{~cm}$ do Latossolo Vermelho Distrófico típico antes do plantio de Eucalyptus dunnii em Alegrete, RS, fevereiro de 2010.

\begin{tabular}{|c|c|c|c|c|c|c|c|c|c|}
\hline $\begin{array}{c}\text { Densidade } \\
\text { do solo }\end{array}$ & $\begin{array}{l}\text { Areia } \\
\text { grossa }\end{array}$ & $\begin{array}{c}\text { Areia } \\
\text { fina }\end{array}$ & Silte & Argila & $\begin{array}{l}\text { Matéria } \\
\text { orgânica }\end{array}$ & $\mathrm{pH}$ & $\mathrm{Al}$ & $\mathrm{Ca}$ & $\mathrm{Mg}$ \\
\hline $\mathrm{g} \mathrm{cm}^{-3}$ & & & $\%$ & & & 1:2,5 ́̊gua & \multicolumn{3}{|c|}{ cmolc $\mathrm{dm}^{-3}$} \\
\hline 1,52 & 33 & 45 & 7 & 15 & 1,00 & 4,74 & 1,99 & 0,46 & 0,33 \\
\hline $\mathrm{P}$ & $\mathrm{K}$ & $\mathrm{S}$ & B & $\mathrm{Cu}$ & $\mathrm{Zn}$ & $\mathrm{CTC}_{\text {efetiva }}$ & $\mathrm{CTC}_{\mathrm{pH} 7}$ & $\mathrm{~V}$ & $\mathrm{~m}$ \\
\hline \multicolumn{6}{|c|}{$\mathrm{mg} \mathrm{dm}^{-3}$} & \multicolumn{2}{|c|}{ cmolc $\mathrm{dm}^{-3}$} & $\%$ & \\
\hline 1,87 & 20,33 & 2,71 & 0,35 & 2,29 & 0,57 & 2,83 & 8,96 & 9,07 &, 3 \\
\hline
\end{tabular}

Onde: Areia grossa: 2-0,2 mm; Areia fina: 0,2-0,05 mm; Silte: 0,05-0,002 mm; Argila: $<0,002 \mathrm{~mm}$.

T abela 2 - Características do povoamento florestal próximo ao início e final do monitoramento da precipitação em plantio de Eucalyptus dunnii, Alegrete, RS.

\begin{tabular}{lll}
\hline \multirow{2}{*}{ Variável } & \multicolumn{2}{l}{ Idade (meses) } \\
\cline { 2 - 3 } & 15 & 27 \\
\hline Árvores (ha) & 1345 & 1281 \\
Falhas (ha)* & 83 & 147 \\
DAP (cm) & 4,7 & 9,0 \\
Altura (m) & 4,5 & 8,7 \\
Volume cilíndrico $\left(\mathrm{m}^{3} \mathrm{ha}^{-1}\right)$ & 13 & 87 \\
\hline
\end{tabular}

Onde: DAP = diâmetro à altura do peito (1,3 $\mathrm{m}$ da superfície
do solo); * devido a mortalidade natural de plantas.

O monitoramento se iniciou quando o povoamento estava com 16,5 meses de idade (referente ao mês de abril de 2010) e terminou quando o povoamento tinha 28,5 meses de idade (referente ao mês de março de 2011). Para a realização do monitoramento foram demarcadas quatro parcelas medindo $20 \mathrm{~m}$ x $21 \mathrm{~m}$. Em cada parcela monitorou-se a precipitação, através de coletores de precipitação interna (PI) e de coletores da precipitação resultante do escorrimento pelo tronco (ET).

Em cada uma das quatro parcelas retangulares, foram instalados três coletores para a quantificação da precipitação interna com localização nas posições linha, entrelinha e diagonal, totalizando 12 coletores para precipitação interna. Estes coletores foram compostos basicamente por um recipiente de armazenagem e um funil com $16 \mathrm{~cm}$ de diâmetro interno (Figura 3); cuja borda estava situada a uma altura de $1 \mathrm{~m}$ da superfície do solo. Já para o escorrimento pelo tronco, em cada parcela foram instalados um total de três coletores da precipitação no seguinte arranjo: um em uma árvore que se apresentava próxima ao DAP médio, outro em uma árvore de DAP médio mais um desvio padrão e outro, por fim, em árvore com DAP médio menos um desvio padrão. Estes coletores constavam de funil, mangueira e recipiente coletor com capacidade para estoque de $60 \mathrm{~L}$, montados com o auxílio de espuma de poliuretano e cola de silicone (Figura 3). Já para a precipitação global foram instalados 2 coletores situados a cerca de $40 \mathrm{~m}$ do plantio e com aproximadamente $10 \mathrm{~m}$ de distância entre si. Os coletores eram idênticos aos de precipitação interna, mas a borda do funil foi instalada com altura de 1,5 m em relação à superfície do solo (Figura 1). 
Corrêa et al.

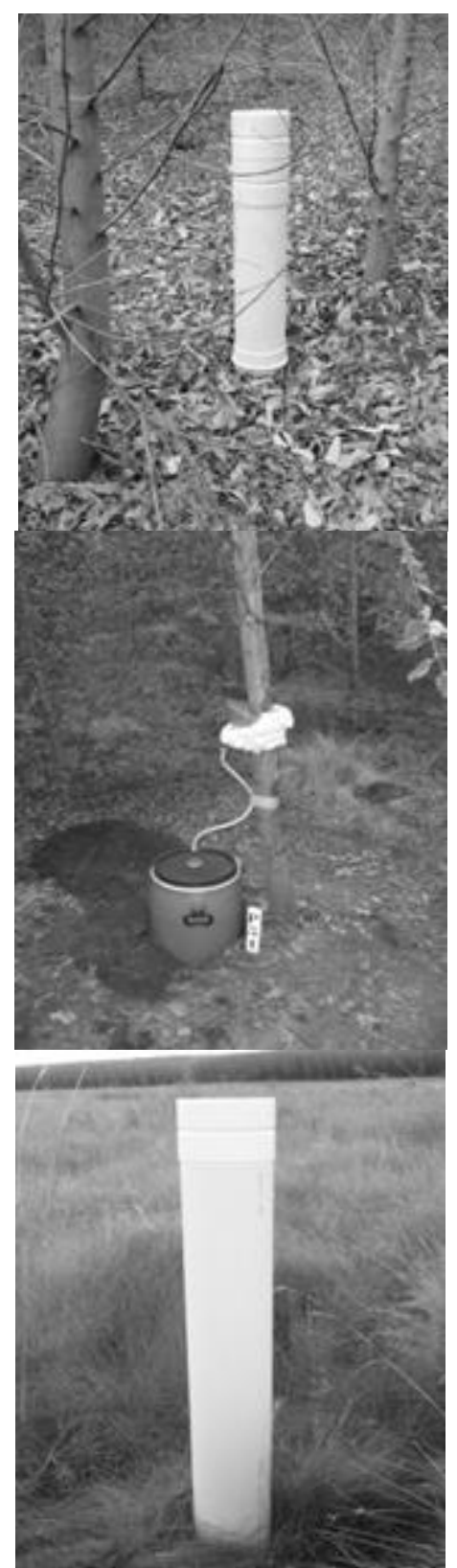

Figura 1 - Aspecto de coletores utilizados no monitoramento da precipitação em plantio de Eucalyptus dunnii, Alegrete, RS. Onde: À esquerda = coletor de precipitação interna; ao centro = coletor de precipitação do escorrimento pelo tronco; à direita $=$ coletor de precipitação global.

As coletas foram realizadas quinzenalmente e mensuravase, através de proveta graduada ou balde graduado, o volume precipitado individualmente em cada coletor. Para os valores individuais de precipitação em cada coletor, foram adotadas a expressão $p p=\frac{v}{a}$ para precipitação interna e precipitação global e a expressão $p p=\frac{v}{g} \times \frac{G}{A}$ para o escorrimento pelo tronco; onde $p p$ é a precipitação (mm), $v$ é o volume coletado (L), $a$ é a área do coletor $\left(\mathrm{m}^{2}\right), g$ é a área basal da árvore $\left(\mathrm{m}^{2}\right)$, $G$ é a área basal da parcela $\left(\mathrm{m}^{2}\right)$ e $A$ é a área da parcela $\left(\mathrm{m}^{2}\right)$ (Preuhsler et al. 2006).

No cálculo da média quinzenal de cada parcela para precipitação interna e escorrimento pelo tronco adotou-se a média aritmética dos valores de cada um dos coletores, considerando-se os dados resultantes dos procedimentos já mencionados. O valor mensal resultou da soma dos valores quinzenais. A soma dos valores de precipitação interna e escorrimento pelo tronco resultou na precipitação efetiva
(PE), ou seja, a precipitação que chega ao solo florestal após atravessar o dossel.

Todos os resultados foram analisados de acordo com o delineamento blocos completos ao acaso, e, em caso de diferença estatística significativa, foram analisados segundo o teste de Tukey, ambos ao nível de $5 \%$ de probabilidade de erro. Também foram realizados testes de correlação de Pearson entre variáveis de precipitação.

\section{Resultados e discussão Precipitação global}

O volume de precipitação global registrado na área de estudo foi de $1586 \mathrm{~mm}$ (Tabela 3). A precipitação global apresentou uma média mensal de $132 \mathrm{~mm}$ e elevada variabilidade ao longo do ano $(\mathrm{CV}=63 \%)$, com novembro representando apenas $2 \%$ da precipitação anual e setembro representando $17 \%$ da precipitação anual, ou seja, o mês com menor precipitação representou apenas $12 \%$ da precipitação do mês com maior precipitação.

\section{Precipitação efetiva}

A precipitação efetiva correspondeu a $93 \%$ da precipitação global e apresentou elevada variação ao longo dos meses quando se consideraram os valores absolutos (CV $=64 \%$ ), com menor valor no mês de novembro e valor máximo no mês de setembro. No entanto, quando se considera a relação percentual PE/PG, a variabilidade anual mostra-se baixa $(\mathrm{CV}=5 \%)$. Este mesmo comportamento em termos de variabilidade foi verificado para precipitação interna, que compõe $98 \%$ da precipitação efetiva.

Os valores do escorrimento pelo tronco representam uma média de apenas $1 \%$ da precipitação global e são responsáveis por apenas $2 \%$ da precipitação efetiva. Seus valores apresentam-se com maior variabilidade ao longo do ano $(\mathrm{CV}=78 \%)$ e quando considerada a relação percentual $\mathrm{ET} / \mathrm{PG}$, a variabilidade atinge valores moderados $(\mathrm{CV}=30$ $\%)$.

Tabela 3 - Precipitação global (PG), escorrimento pelo tronco (ET), precipit ação interna (PI), precipitação efetiva (PE) e interceptação (I) ao longo de um ano de monit oramento em um plantio de Eucalyptus dunnii, Alegrete, RS.

\begin{tabular}{cccccc}
\hline Mês/An & PG & ET & PI & PE & I \\
\cline { 2 - 6 } o & \multicolumn{5}{c}{$\mathrm{mm}$} \\
\hline $04 / 2010$ & $169,2 \pm 0,4$ & $1,4 \pm 0,6 \mathrm{ef}$ & $152,3 \pm 2,7$ & $153,7 \pm 2,5$ & $15,5 \pm 2,3 \mathrm{ab}$ \\
& $\mathrm{d}$ & $\mathrm{d}$ & $\mathrm{d}$ & \\
$05 / 2010$ & $106,0 \pm 0,7$ & $1,1 \pm 0,2 \mathrm{ef}$ & $104,1 \pm 1,0 \mathrm{f}$ & $105,2 \pm 1,0 \mathrm{e}$ & $0,8 \pm 1,0 \mathrm{~b}$ \\
& $\mathrm{~g}$ & & & & \\
$06 / 2010$ & $44,7 \pm 1,6 \mathrm{i}$ & $0,7 \pm 0,1 \mathrm{f}$ & $41,2 \pm 1,8 \mathrm{~h}$ & $41,9 \pm 1,8 \mathrm{~g}$ & $2,8 \pm 1,4 \mathrm{~b}$ \\
& $248,5 \pm 3,6$ & $2,0 \pm 0,8 \mathrm{~cd}$ & $235,7 \pm 4,1$ & $237,7 \pm 4,2$ & $10,8 \pm 2,8 \mathrm{ab}$ \\
$07 / 2010$ & $\mathrm{~b}$ & $\mathrm{e}$ & $\mathrm{b}$ & $\mathrm{b}$ & \\
& & & & \\
$08 / 2010$ & $32,7 \pm 0,0 \mathrm{j}$ & $0,5 \pm 0,1 \mathrm{f}$ & $29,4 \pm 1,3 \mathrm{~h}$ & $29,9 \pm 1,3 \mathrm{~g}$ & $2,9 \pm 1,3 \mathrm{~b}$ \\
$09 / 2010$ & $269,7 \pm 0,4 \mathrm{a}$ & $5,7 \pm 1,2 \mathrm{a}$ & $258,4 \pm 4,9 \mathrm{a}$ & $264,1 \pm 5,1 \mathrm{a}$ & $5,5 \pm 5,2 \mathrm{~b}$ \\
$10 / 2010$ & $82,7 \pm 0,5 \mathrm{~h}$ & $1,5 \pm 0,3 \mathrm{def}$ & $75,8 \pm 3,2 \mathrm{~g}$ & $77,3 \pm 3,5 \mathrm{f}$ & $5,4 \pm 3,6 \mathrm{~b}$ \\
$11 / 2010$ & $32,0 \pm 0,4 \mathrm{j}$ & $0,6 \pm 0,1 \mathrm{f}$ & $29,1 \pm 0,9 \mathrm{~h}$ & $29,7 \pm 1,0 \mathrm{~g}$ & $2,3 \pm 1,2 \mathrm{~b}$ \\
& & & $135,4 \pm 2,0$ & $10,4 \pm 3,1 \mathrm{~b}$ \\
$12 / 2010$ & $145,8 \pm 2,8 \mathrm{e}$ & $2,7 \pm 0,5 \mathrm{bc}$ & $132,6 \pm 2,3 \mathrm{e}$ & $\mathrm{d}$ & \\
& & & & & $17,1 \pm 10,0 \mathrm{a}$ \\
$01 / 2011$ & $99,7 \pm 2,8 \mathrm{~g}$ & $1,1 \pm 0,2 \mathrm{ef}$ & $81,5 \pm 9,3 \mathrm{~g}$ & $82,6 \pm 9,3 \mathrm{f}$ & $\mathrm{b}$ \\
\hline \multirow{2}{*}{$02 / 2011$} & $229,8 \pm 3,1 \mathrm{c}$ & $3,7 \pm 0,8 \mathrm{~b}$ & $200,5 \pm 4,3 \mathrm{c}$ & $204,1 \pm 4,3 \mathrm{c}$ & $25,7 \pm 3,2 \mathrm{a}$ \\
$03 / 2011$ & $125,2 \pm 1,1 \mathrm{f}$ & $2,5 \pm 0,9 \mathrm{~cd}$ & $112,9 \pm 3,9 \mathrm{f}$ & $115,5 \pm 4,6 \mathrm{e}$ & $9,7 \pm 4,6 \mathrm{ab}$ \\
\hline \multirow{2}{*}{ Soma* } & 1586,1 & 23,5 & 1453,6 & 1477,1 & 109,0 \\
& $(100,0)$ & $(1,5)$ & $(91,6)$ & $(93,1)$ & $6,9)$ \\
\hline & & & & & \\
\hline
\end{tabular}

Onde: valores $=$ média \pm desvio padrão; $*$ valores entre parênteses representam a \% em relação à precipitação global; letras diferentes para uma mesma coluna representam 
diferenças estatísticas significativas entre os meses pelo Teste de Tukey a $5 \%$ de probabilidade de erro.

A interceptação foi de $7 \%$ da precipitação global e apresentou a maior variabilidade encontrada, tanto para valores absolutos entre os meses $(\mathrm{CV}=82 \%)$ quanto para a relação percentual $\mathrm{I} / \mathrm{PG}(\mathrm{CV}=58 \%)$. Entre os meses ocorreram mínimos de $1 \%$ em maio e máximos de $17 \%$ em janeiro. Coincidentemente estes dois meses tiveram uma precipitação global da mesma ordem, cerca de $100 \mathrm{~mm}$, no entanto, em maio, $93 \%$ da precipitação ocorreu na segunda quinzena do mês e, em janeiro, a precipitação foi melhor distribuída, a segunda quinzena correspondeu a $49 \%$ da precipitação mensal. Assim, a distribuição da chuva de maneira mais homogênea aumentou a interceptação.

Outras espécies e ecossistemas florestais apresentam diferentes respostas em relação à precipitação global. Caldato (2011) encontrou escorrimento pelo tronco de $6 \%$ em relação a precipitação efetiva e interceptação de $25 \%$ da precipitação global $(2228 \mathrm{~mm})$ ao estudar um povoamento de Pinus taeda com densidade inicial de 1429 árvores ha $^{-1}$ e 12 anos de idade. Já Arcova et al. (2003) encontraram uma interceptação de 18 $\%$ em relação à precipitação global $(2220 \mathrm{~mm})$, em área de regeneração de Mata Atlântica com cerca de 45 anos de idade. Variações em parâmetros da precipitação podem ser atribuídos ao tipo e idade da formação vegetal existente, por isso, é importante o entendimento da dinâmica de cada floresta de acordo com o bioma em que está inserida, uma vez que isso influencia diretamente na interação da floresta com a precipitação incidente. Além dos fatores intrínsecos à floresta, há de se considerar também a quantidade da precipitação, pois mesmo se considerando floresta de eucalipto com mesma idade e com menor número de indivíduos por hectare, Baumhardt (2010) encontrou o dobro de interceptação, mas com valor de precipitação global $20 \%$ menor.

Utilizando-se os valores mensais de precipitação interna, ET, precipitação efetiva, precipitação global e de interceptação (em mm e \%), pode-se afirmar que ocorreu correlação positiva entre quaisquer valores da precipitação interna, precipitação efetiva, precipitação global e escorrimento pelo tronco, ou seja, quando ocorreu maior precipitação, houve aumento no volume coletado, em todas as formas de precipitação (Tabela 5). Embora a mesma explicação seja válida para a interceptação $(\mathrm{mm})$, somente a precipitação global teve correlação significativa com esta variável. Já em relação à interceptação percentual, a única correlação significativa ocorreu com a interceptação $(\mathrm{mm})$, pois são apenas formas diferentes de demonstrar o comportamento da precipitação. Ainda em relação à interceptação percentual, as demais correlações nãosignificativas, mas negativas, resultam, provavelmente, de elevadas precipitações em períodos de baixo déficit de saturação de vapor na atmosfera e/ou pela ocorrência de precipitação em um dossel umedecido (Tabela 5).
T abela 5 - Coeficiente de correlação simples (valor ${ }^{\text {significância }}$ ) entre os valores médios mensais, em mm, de precipitação global (PG), escorrimento pelo tronco (ET), precipitação interna (PI), precipitação efetiva (PE) e interceptação (INT - em mm e \%) em um ano de monit oramento em plantio de Eucalyptus dunnii, em Alegrete, RS

\begin{tabular}{cccccc}
\hline & PI & PE & PG & INT & INT\% \\
\hline ET & $0,83^{*}$ & $0,83^{*}$ & $0,83^{*}$ & $0,33^{\text {ns }}$ & $-0,25^{\text {ns }}$ \\
PI & & $>0,99^{*}$ & $>0,99^{*}$ & $0,46^{\text {s }}$ & $-0,27^{\text {ns }}$ \\
PE & & & $>0,99^{*}$ & $0,46^{\text {ss }}$ & $-0,27^{\text {ns }}$ \\
PG & & & & $0,53^{* * *}$ & $-0,20^{\text {ns }}$ \\
INT & & & & & $0,65^{* * *}$ \\
\hline
\end{tabular}

Onde: $*=$ significativo a $1 \% ; * *=$ significativo a $5 \% ; * * *$ = significativo a $10 \% ;{ }^{\text {ns }}=$ não significativo.

Arcova et al. (2003), em função do processo de fracionamento da água das chuvas pela floresta ser influenciado pelas condições das precipitações, optaram por agrupar e analisar resultados em dois períodos distintos do ano, caracterizados por período chuvoso e pouco chuvoso. Silva e Rodríguez (2001) não relataram escorrimento pelo tronco nas coletas realizadas após cada evento de precipitação, em precipitações menores que 4; 5 e 6,5 mm em floresta de carvalho (312 árvores $\mathrm{ha}^{-1}$ ), floresta mista de carvalho e pinus (466 árvores ha ${ }^{-1}$ ) e floresta de pinus (246 árvores $\mathrm{ha}^{-1}$ ), respectivamente, em local em que ocorreu 375 $\mathrm{mm}$ ano $^{-1}$ durante o período de avaliação.

Outras fontes de variação, especificamente em relação ao gênero Eucalyptus, foram relatadas por Whitehead e Beadle (2004), que conseguiram identificar diversos mecanismos de passagem da precipitação pelo dossel para evitar seca, dentre os quais se podem relacionar os baixos valores do índice de área foliar e a grande variação dinâmica sazonal no índice de área foliar, além do arranjo foliar próximo à vertical.

\section{Conclusão}

A interceptação foi de $7 \%$ da precipitação global e a precipitação efetiva de $98 \%$. O escorrimento pelo tronco foi de $2 \%$ da precipitação efetiva. Em plantio jovem de eucalipto houve pouca interação da precipitação com o povoamento.

\section{Agradecimentos}

À Coordenação de Aperfeiçoamento de Pessoal de Nível Superior (CAPES) pela concessão de bolsa de estudos. À Empresa Stora Enso S/A pela cedência do povoamento onde o estudo foi realizado.

\section{Referências}

ABRAF (2009) Anuário estatístico da ABRAF: ano base 2008. Brasília: ABRAF. 120p.

ABRAF (2010) Anuário estatístico da ABRAF 2010 ano base 2009. Brasília: ABRAF. 140p.

ABRAF (2012) Anuário estatístico da ABRAF 2012 ano base 2011. Brasília: ABRAF. 150p.

ARCOVA FCS, CICCO V, ROCHA PAB (2003) Precipitação efetiva e interceptação das chuvas por floresta de mata atlântica em uma microbacia experimental em Cunha - São Paulo. Árvore, 27(2):257-262. doi: 10.1590/S0100-67622003000200014

BAUMHARDT E (2010) Balanço hídrico de microbacia com eucalipto e pastagemnativa na região da campanha do $R S$. Dissertação, Universidade Federal de Santa Maria, Santa Maria. 139p. 
CALDATO SL (2011) Ciclagem biogeoquímica dos nutrientes em uma plantação de Pinus taeda L. no nordeste argentino. Tese, Universidade Federal de Santa Maria. $106 \mathrm{p}$.

CONSEMA. Resolução Consema $N^{o}$ 227/2009. Aprova alterações do Zoneamento Ambiental para a Atividade de Silvicultura no Estado do Rio Grande do Sul de que trata a Resolução CONSEMA n ${ }^{\circ}$ 187, de 09 de abril de 2008 e dá outras providências. Volume I: Estrutura, metodologia e resultados. 137p. Disponível em: <www.fepam.rs.gov.br>. Acesso: 28 fev. 2011.

GONÇALVES JLM., STAPE JL, BENEDETTI V, FESSEL VAG, GAVA JL. An evaluation of minimum and intensive soil preparation regarding fertility and tree nutrition. In: GONÇALVES JLM. (Ed.) Forest Nutrition and Fertilization. 2 edição. São Paulo: IPEF. p. 46-62.

IBÁ - INDÚSTRIA BRASILEIRA DE ÁRVORES (2017) Relatório anual 2017. Brasília: IBÁ. Disponível em: <https://www.iba.org/publicacoes>. Acesso em: 28 nov. 18.

IBÁ - INDÚSTRIA BRASILEIRA DE ÁRVORES (2018). Sumário Executivo 2018. Disponível em: https://www.iba.org/datafiles/publicacoes/relatorios/digital -sumarioexecutivo-2018.pdf. Acesso em: 04 nov. 19.

IBGE - INSTITUTO BRASILEIRO DE GEOGRAFIA E ESTATÍSTICA (2016). Produção da Extração Vegetal e da Silvicultura 2016. Disponível em: <https://www.ibge.gov.br/estatisticas >. Acesso em: 01 jun. 19.

KIM MINS JP (1987) Forest ecology. New York: Macmillan. $531 \mathrm{p}$.

MACHADO CC, SILVA EN, PEREIRA RS (2008) O setor florestal brasileiro e a colheita florestal. In: MACHADO, C.C. (Ed.) Colheita Florestal. $2^{\mathrm{a}}$ edição. Viçosa: UFV. p.15-42.

MALUF JRT (2000) Nova classificação climática do Estado do Rio Grande do Sul. Revista Brasileira de Agrometeorologia, 8(1):141-150.

MARQUES R, PIAZZA GE, BLUM H, PINTO CB, BIANCHIN JE, DALM ASO CA, DICKOW KMC (2015) Contribuição da precipitação interna para o aporte de nutrientes em estágios sucessionais da Floresta Atlântica no Paraná. Scientia Agraria, 16:80-95. doi: 10.5380/rsa.v16i3.46879

PREUHSLER T, BASTRUP-BIRK A, BEUKER E (2006) Manual on methods and criteria for harmonized sampling, assessment, monitoring and analysis of the effects of air pollution on forests - Part VII: Meteorological Measurements. 32p. Disponível em: < http://www.icpforests.org/ >. Acessado em: 8 mar. 2011.

SANTOS HG, JACOMINE PKT, ANJOS LHC, OLIVEIRA VA, LUMBRERAS JF, COELHO MR, ALMEIDA JA, ARAÚJO FILHO JC, OLIVEIRA JB, CUNHA TJF (2018) Sistema Brasileiro de Classificação de Solos. $5^{\mathrm{a}}$ edição. Brasília, DF: Embrapa. 476p.

SILVA IC, RODRÍGUEZ HG (2001) Interception loss, throughfall and stemflow chemistry in pine and oak forests in northeastern Mexico. Tree physiology, 21(12-13):10091013. doi: 10.1093/treephys/21.12-13.1009

SILVEIRA ALL (1993) Ciclo hidrológico e bacia hidrográfica. In: TUCCI CEM (Org.) Hidrologia: ciência e aplicacão. Porto Alegre: Editora da Universidade/ABRH/ EDUSP. 943p. p.35-51.

Silviconsult Engenharia. Estudo de Impacto Ambiental Empreendimento Florestal Derflin Agropecuária: Vol. III Meio Biótico. 2007a.

Silviconsult Engenharia. Estudo de Impacto Ambiental Empreendimento Florestal Derflin Agropecuária: Mapas Gerais - Solos. 2007b.

TUCCI CEM (1993) Interceptação. In: TUCCI CEM (Org.) Hidrologia: ciência e aplicação. Porto Alegre: Editora da Universidade/ABRH/EDUSP. p.243-252.

WHITEHEAD D, BEADLE CL (2004) Physiological regulation of productivity and water use in Eucalyptus: a review. Forest Ecology and Management, 193:113-140. doi: 10.1016/j.foreco.2004.01.026 